\author{
Владимир Плунгян \\ Институт русского языка им. В. В. Виноградова РАН \\ plungian@iling-ran.ru \\ Vladimir Plungian \\ V. V. Vinogradov Russian Language Institute, RAS \\ plungian@iling-ran.ru
}

\title{
ГЕОМЕТРИЯ РУССКОГО СЛОВОИЗМЕНЕНИЯ: О ТРАДИЦИОННЫХ И НЕТРАДИЦИОННЫХ ТАБЛИЦАХ СКЛОНЕНИЯ
}

\section{THE GEOMETRY OF RUSSIAN INFLECTION: ON TRADITIONAL AND NON-TRADITIONAL DECLENSION TABLES}

В статье обсуждается ряд теоретических проблем русского словоизменения с точки зрения технической (на первый взгляд) задачи создания оптимальной таблицы склонения русских имен. Эти проблемы можно разбить на три группы. К первой группе относится иерархия падежных граммем, а также связанный с ней порядок падежей в парадигме. Ко второй группе относится набор типов склонения (словоизменительных типов, возникающих в силу алломорфического варьирования показателей, выражающих одинаковый набор граммем), а также представление этого алломорфического варьирования в словоизменительных парадигмах. Наконец, к третьей группе относится проблема определения места форм партитива («второго родительного») и аднумератива («счётной формы») в системе русского склонения; эта проблема в русистике обсуждались относительно меньше, но она тесно связана с проблемами предыдущих двух групп.

Ключевые слова: русский язык, морфология, словоизменение имени, падеж, число, род, геометрические модели, таблицы.

The paper discusses a number of theoretical issues related to Russian inflection from a rather technical perspective of building an optimal table for Russian nominal declension. These issues can be divided into three groups. The first group includes the hierarchy of case grams, as well as the order of cases in the table (implied by this hierarchy). The second group includes the inventory of declension classes (determined by allomorphic variation within the markers of one and the same gram), as well as the strategies of representing this allomorphic variation in inflectional paradigms. Finally, the third group includes the status of partitive (or "second genitive") and adnumerative (or "counting form") in the system of Russian declension; this latter problem has received relatively less attention, but it is closely related to the previous two groups.

Keywords: Russian, morphology, nominal inflection, case, number, gender, geometric models, tables. 


\section{1. Вводные замечания}

Использование простейших геометрических инструментов (таких, как схемы, карты и таблицы разного типа) для описания словоизменения флективных языков и моделирования теоретических понятий словоизменительной морфологии - давняя традиция, в историю которой мы в этих кратких заметках вдаваться не будем. Эта техника приобрела особую популярность в XX веке в связи с распространением структуралистских моделей языка, но удержалась и в постструктуралистской лингвистике: достаточно вспомнить успех «семантических карт», ставших едва ли не главным достижением современной теории грамматикализации ${ }^{1}$. Не стоит забывать и о различных современных теориях словоизменительных парадигм, где геометрическое моделирование пространства грамматических значений лексем также широко применяется (для обсуждаемой ниже проблематики наиболее значима, по-видимому, работа McCreight \& Chvany 1991; ср. также Plank 1991, Harley \& Ritter 2002, Caha 2009 и Blevins 2016 с цитируемой там литературой).

В настоящих заметках мы, однако, не ставим цель подробного разбора всех теоретических аспектов «геометрического» подхода к описанию словоизменения (хотя они, безусловно, многообразны и значимы для современной лингвистики). Наша цель гораздо более скромная - попытаться указать на некоторые менее тривиальные следствия такого подхода для описания современного русского склонения. Мы будем опираться на известные идеи, высказанные в свое время (в разной форме и с разной степенью полноты) в работах Н. Н. Дурново, Р. О. Якобсона, А. А. Зализняка, К. Чвани и ряда других авторов, попытавшись, если можно так выразиться, заострить эти идеи, чтобы иметь возможность взглянуть на привычные факты русского именного склонения с новой стороны.

Однако прежде чем мы приступим к анализу фактов русского склонения, полезно сформулировать основную идею, стоящую за геометрическим моделированием флективного склонения (обычно такая модель имеет форму таблицы, в клетках которой помещаются показатели, кумулятивно выражающие сочетания граммем соответствующей строки и столбца). Этот способ представления словоизменительных парадигм кажется настолько простым и привычным, что стоящую за ним идеологию часто принято не замечать (или считать чем-то само собой разумеющимся). Между тем, основной описательный эффект такого способа представления заключается в идее неслучайной пространственной смежности: показатели в соседних клетках таблицы считаются более близкими друг к другу по некоторому набору параметров (конкретный характер которых зависит от языка, но набор которых обнаруживает тенденцию к универсальности). При этом самым главным свойством словоизменительных парадигм, которое нагляд-

1 Ср., в числе многих других работ, Haspelmath 2003, van der Auwera 2013, Georgakopoulos \& Polis 2018. 
но отображается при таком представлении, оказывается, как можно полагать, синкретизм грамматических показателей (понимаемый как любое совпадение показателей в различных клетках таблицы, независимо от степени его систематичности, регулярности, диахронических источников и т. п.).

Синкретизм - важное формальное и содержательное свойство словоизменительных парадигм (особенно флективных), которое интенсивно изучается в современной теоретической морфологии (ср., в частности, Ваеrman et al. 2005, Аркадьев 2005, Arkadiev 2009, Blevins 2016). Но наглядное геометрическое представление синкретизма - давняя идея (не всегда даже эксплицитно осознававшаяся); в ее основе лежит очень простой принцип, согласно которому синкретичные показатели предпочтительно должны занимать смежные клетки парадигмы (и далее могут объединяться: в таком случае число клеток парадигмы будет соответствовать не числу всех возможных комбинаций грамматических значений у данной лексемы, а только числу всех различных манифестаций этих комбинаций).

Из сказанного следует, что вид грамматических таблиц при таком подходе не может быть произвольным: из многих возможных способов упорядочивания граммем в двумерном пространстве таблицы выбирается такой, который обеспечивает оптимальное представление парадигматического синкретизма. Проблема здесь, конечно, состоит в том, что единственного оптимального варианта может не оказаться, и придется выбирать между несколькими конкурирующим представлениями (например, в пользу систематического синкретизма по сравнению с несистематическим; о различении этих двух типов синкретизма см., например, Plank 1991, Arkadiev 2009). Однако это в любом случае адекватнее традиционных способов представления, в которых порядок граммем в таблице часто определяется внешними привходящими обстоятельствами, не имеющими отношения к структурным особенностям парадигмы.

Попытка создать «оптимальную» (в указанном выше смысле) таблицу для показателей русского склонения обнаруживает ряд теоретических проблем, часть из которых обсуждалась в русистике достаточно интенсивно, а часть - оставалась в относительной тени. На наш взгляд, эти проблемы можно разбить на три группы. К первой группе относится иерархия падежных граммем, а также связанный с ней оптимальный порядок падежей в парадигме. Ко второй группе относится число типов склонения (словоизменительных типов, возникающих в силу алломорфического варьирования показателей, выражающих одинаковый набор граммем), а также оптимальное представление этого алломорфического варьирования в словоизменительных парадигмах. Наконец, к третьей группе относится проблема определения места форм партитива («второго родительного») и аднумератива («счётной формы») в системе русского склонения; эта проблема в русистике обсуждались относительно меньше, но она тесно связана с проблемами предыдущих двух групп. 
Ниже мы кратко обозначим возможные решения этих проблем, вытекающие из максимального учета оптимальной геометрической конфигурации таблиц русского склонения. Некоторые из этих решений сегодня фактически общеприняты в описаниях русской морфологии (хотя и не вполне совпадают с традиционными описаниями середины XX века), но некоторые другие могут показаться непривычными даже искушенному морфологу. Соответственно, во втором разделе будет обсуждаться иерархия падежных граммем, в третьем - типы склонения, а в четвертом - партитив и аднумератив.

\section{2. Иерархия русских падежных граммем}

Мы исходим из того, что в современном русском склонении выделяется в общей сложности 10 различных падежных граммем: номинатив (Nom), аккузатив (Acc), генитив (Gen), партитив (Part, он же «второй родительный»), датив (Dat), инструменталис (Ins), предложный падеж (Pr), локатив (Loc, он же «второй предложный»), вокатив $(\mathrm{Voc})^{2}$, аднумератив (Adn, он же «счётная форма»). Вопрос о критериях выделения падежей и их возможном количестве широко обсуждался в литературе и в целом был решен уже в работах 1960-1970-х гг. (см. в первую очередь Зализняк 1967a/2002 и Зализняк 1973/2002; отметим также, что все 10 граммем учитываются, например, в морфологической разметке Национального корпуса русского языка). Однако проблема здесь не столько в количестве выделяемых падежных граммем, сколько в том, что данный инвентарь падежей (как бы и на каких бы основаниях его ни выделять) в высокой степени неоднороден и объединяет - в рамках единой грамматической категории элементы с очень разными свойствами ${ }^{3}$.

Для понимания структуры и принципов диахронической эволюции русской падежной системы целесообразно выделять три разных подмножества падежных граммем, требующих разного подхода и разной техники описания.

(i) Это, во-первых, пять «базовых» падежей, в число которых входят Nom, Gen, Dat, Pr и Ins. Данные падежи наиболее близки к прототипическому представлению о падежной граммеме: они не имеют лексических ограничений на образование (т. е. свойственны всем русским именам), обладают каждый самостоятельным набором показателей (с относительно небольшой долей падежного синкретизма между элементами этого спи-

2 Имеется в виду прежде всего так наз. «новый вокатив», образуемый усечением конечного - $a$ номинатива; подробнее об этой форме см., в частности, Даниэль 2009, Andersen 2012, Janda 2019.

3 Заметим, что такая ситуация вообще типологически частотна и является скорее правилом, чем исключением; она особенно характерна для «немолодых» грамматических категорий флективных языков, прошедших длительную диахроническую эволюцию и включающих граммемы разного происхождения, входивших в состав категории на разных этапах истории языка. 
ска - и лишь в отдельных подтипах склонения) и в целом составляют ядро словоизменительной парадигмы имени ${ }^{4}$.

(ii) Во-вторых, это «слабо дифференцированные» (в смысле Зализняк 1973 / 2002), но парадигматически существенные падежи: к таковым относится прежде всего Асс, а также, как мы намерены более подробно показать в следующем разделе, Part и Adn. Эти падежи специализируются на выражении частотных семантико-синтаксических функций (в сфере объектных, посессивных и количественных отношений) и в этом смысле составляют важную часть русской падежной системы, однако они практически не имеют собственных падежных показателей, демонстрируя высокую степень синкретизма и морфологической несамостоятельности. Важным обстоятельством является и то, что все эти три падежа (наряду с Nom и Gen) принимают активное участие в формировании механизмов дифференцированного маркирования объекта и субъекта, характерных для современного русского литературного и диалектного синтаксиса (см., в частности, Daniel 2014, Igartua \& Madariaga 2018, Малышева \& Ронько 2020). Морфологически самостоятельный аккузатив имеется в русском языке лишь у форм ед. числа женского морфологического рода (тип F в таблице 1 ниже), партитив и аднумератив выделяются только у форм ед. числа мужского морфологического рода (тип М). Интересно при этом, что «маргинализация» аккузатива — результат длительного диахронического процесса, общего для всех славянских языков, тогда как появление в русской падежной системе партитива и аднумератива - результат сравнительно недавних локальных инноваций; постепенная утрата «старого» падежа и появление двух «новых» в данном случае одинаково способствовали образованию внутри русской падежной системы переходной зоны слабо дифференцированных синтаксических падежей.

(iii) В-третьих, это слабо дифференцированные и «экстрапарадигматичные» падежи, к каковым относятся Loc и Voc. Как и падежи предыдущей группы, они практически не имеют собственных падежных показателей и при этом характеризуются очень узкой сочетаемостью; но, в отличие от падежей предыдущей группы, они практически не участвуют и в выражении главных синтаксических отношений. В этом смысле их и можно назвать экстрапарадигматичными: они максимально далеки от понятия прототипического падежа и фактически находятся вне падежной парадигмы, составляя некоторое локальное расширение падежной парадигмы у ограниченного числа существительных. Тем не менее, несмотря на свой маргинальный статус, они, безусловно, входят в русскую падежную систему.

Таким образом, общий взгляд на структуру русских падежей «через призму таблицы склонения» позволяет увидеть противопоставление базо-

4 Ср. близкие понятия «первичных словоформ» и «суженной парадигмы», введенные в Зализняк 1967a/2002: 133-134 для описания формальных правил образования именных парадигм. 
вых падежей, хорошо встроенных в таблицу, и маргинальных падежей, фактически в таблицу не встроенных: эти падежи выражаются морфологически самостоятельными показателями (не совпадающими с показателями других падежей) лишь у небольшого числа имен. Данное противопоставление не имеет жесткого характера и образует обширную переходную зону, внутри которой парадигматичность падежа постепенно убывает. Любопытно, что в эту переходную зону попадает и аккузатив - исторически единственный из непарадигматических падежей, существовавший в общеславянский период. Можно сказать, что экстрапарадигматическая зона в русском склонении в каком-то смысле и возникла на скрещении двух тенденций: постепенной маргинализации общеславянского аккузатива и появления значительного числа слабо дифференцированных и морфологически несамостоятельных падежей вследствие процессов перестройки древнерусской системы склонения (завершившихся к XVI-XVII вв.).

Нельзя не отметить бросающегося в глаза сходства по обоим параметрам современной русской системы склонения с падежными системами уральских языков (прежде всего, прибалтийско-финских), что, в принципе, является хорошо известным фактом. И маргинализация аккузатива (с постепенным вытеснением его из падежной системы через стадию дифференцированного маркирования объекта), и особая роль партитива в падежной системе, и появление грамматически периферийных экстрапарадигматических падежей в результате процессов исторически недавней грамматикализации или реанализа - всё это является в русском языке следствием реализации ареальных тенденций, которые считаются характерными для циркумбалтийского ареала в целом (ср. подробный обзор этой проблематики в Koptjevskaja-Tamm \& Wälchli 2001: 646-674).

Проблема иерархии падежных граммем тесно связана с другой, более частной, однако важной именно для табличного представления падежных парадигм: это проблема порядка следования падежей в таблице. По крайней мере с конца 1960-х гг. по этому поводу установился консенсус в пользу порядка Nom - Acc — Gen - Pr — Dat - Ins. Он не совпадает с традиционным (прежде всего в отношении позиции Асc), но именно такой порядок оптимальным образом отражает системный парадигматический синкретизм у русских показателей склонения ${ }^{5}$, а также задает естественную классификацию русских базовых падежей, от более синтаксических, связанных с выражением главных синтаксических отношений, до более семантически нагруженных и связанных с выражением многообразных периферийных семантических ролей (адресата, инструмента, места и т. п.).

5 Собственно, именно этот фактор был точно и эксплицитно сформулирован уже в «Русском именном словоизменении» А. А. Зализняка: «Несколько клеток, содержащих одинаковое условное окончание, при записи могут быть объединены. Нетрадиционный порядок падежей <...> нужен как раз для того, чтобы облегчить такие объединения» (Зализняк 1967a/2002: 205). Ср. также более подробное обсуждение и аргументацию в Chvany 1982/1996. 


\section{3. Типы склонения существительных}

Проблема определения количества типов склонения («парадигматических классов»), как уже было отмечено, является в первую очередь проблемой описания алломорфического варьирования у показателей русских падежей, но на самом деле она имеет и более содержательное измерение: попытки ее решения прямо связаны с тем, каким образом решается вопрос о структуре грамматических категорий, образующих словоизменительные парадигмы русских имен.

В этом отношении в работах XX века прослеживается тенденция к отказу от традиционного диахронически ориентированного взгляда на алломорфическое варьирование в русском склонении, при котором ведущую роль играла опора на древние индоевропейские «типы склонения», более или менее явно обнаруживаемые в общеславянском, но практически полностью утраченные в современном русском. Отказ этот может быть более или менее радикальным (и обычно порождает разного рода компромиссные классификации), но, кажется, материал современного русского языка всё же не исключает и максимально радикальные решения (одно из которых мы рассмотрим ниже).

Основных параметров, релевантных для русских парадигматических классов в именном склонении, как представляется, два: это деление в соответствии с «морфологическим родом» (Зализняк 1967a/2002: 146-149; см. также Крылов 2002) и деление в соответствии с морфонологическим типом исхода основы, противопоставляющее морфонологически твердые и морфонологически мягкие основы ${ }^{6}$.

Понятие морфологического рода является для русского склонения крайне важным; оно релевантно в первую очередь для слов так наз. женского морфологического рода. Несколько упрощая, женский морфологический род лексемы - это такой набор флексий, который преимущественно свойствен лексемам женского синтаксического рода (= согласовательного класса); однако морфологический род может не совпадать с синтаксическим. Известными примерами являются лексемы мужского синтаксического рода типа мужчина или юноша, у которых набор флексий такой же, как у слов типа женщина или стена; поэтому синтаксически они относятся к мужскому, а морфологически - к женскому роду. Это понятие удобно, поскольку позволяет однозначно предсказывать парадигматический класс существительного (тогда как синтаксический род существительного это позволяет делать не во всех случаях).

Два названных выше параметра позволяют выделить все релевантные парадигматические классы. Прежде всего, современное русское склонение

6 В исходе морфонологически мягких основ, как известно, не всегда оказываются согласные, имеющие в современном языке палатализованную артикуляцию (как шипящие š и ž, утратившие историческую палатализацию); с другой стороны, основы с исходом на палатальный согласный ј (или на также утративший историческую палатализацию свистящий с) относятся к морфонологически твердым. 
различает стандартный (или «родовой») тип, внутри которого противопоставляются наборы флексий женского и мужского/среднего морфологического рода (последние два набора совпадают у всех падежей, кроме номинатива; напротив, флексия женского рода систематически отличается во всех падежах, кроме предложного). При этом только лексемы женского морфологического рода стандартного типа имеют морфологически самостоятельный аккузатив; во всех остальных типах аккузатив либо совпадает с номинативом, либо является морфологически несамостоятельным, выражаясь с помощью правил дифференцированного маркирования (у одушевленных существительных совпадая с генитивом, а у неодушевленных с аккузативом; в Таблице 1 ниже такой способ выражения аккузатива обозначается как DIF).

Второй тип склонения (так наз. «мягкий») характеризуется тем, что включает только лексемы с основой на морфонологически мягкую согласную. Большинство из них женского синтаксического (и морфологического) рода; различия в наборе флексий у лексем разных морфологических родов невелики и затрагивают только инструменталис 7 .

Таким образом, в русском склонении выделяется стандартный «родовой» тип с подтипами $\mathrm{F}, \mathrm{M}$ и $\mathrm{N}$, в котором набор флексий определяется морфологическим родом, и нестандартный «мягкий» тип с преобладанием лексем женского рода и крайне ограниченным числом лексем среднего и мужского рода (подтипы F2, N2 и M2 в Таблице 1). Подтип N2 представлен группой слов типа знамя; подтип М2 - единственной лексемой $n y m b$. Дифференцированного маркирования объекта по одушевленности в мягком типе нет, аккузатив совпадает с номинативом (как и у лексем типа N).

Нетрудно заметить, что все указанные особенности характеризуют парадигмы единственного числа. Что касается парадигмы множественного числа, то она формируется под влиянием сильной исторической тенденции к унификации противопоставления по морфологическому роду, т. е. к появлению единого набора флексий для всех существительных во множественном числе. В современном языке различия, связанные с морфологическим родом, сохраняются в какой-то степени только в формах номинатива и генитива мн. числа (аккузатив во множественном числе всегда морфологически несамостоятелен). В генитиве ситуация наиболее сложная; в стандартном случае предполагается (Зализняк 1967a/2002: 205-207):

(i) нулевая флексия для твердых типов $\mathrm{F}$ и $\mathrm{N}$, а также для типа $\mathrm{N} 2$;

(ii) флексия -ov для твердого типа M

7 Заметим, что в стандартном типе склонения флексии для твердых и мягких основ морфонологически полностью совпадают - исторически это результат радикальных процессов аналогического выравнивания общеславянских парадигматических классов, характерных для русского языка. Но по общему набору флексий мягкий тип ближе к стандартному женскому; это позволяет говорить о тенденции к формированию «женского» и «неженского» склонения (подкрепленной утратой среднего рода во многих русских диалектах); ср. сходные наблюдения, например, в Nesset 2003. 
(iii) флексия -еј для всех мягких типов (но при этом в мягких типах $\mathrm{F}$ и $\mathrm{N}$ при ударении в $\mathrm{Pr}$, Dat, Ins на основе нулевая флексия также считается стандартной, несмотря на ряд колебаний в реальном узусе).

Даже это стандартное распределение является «родовым» достаточно условно: как можно видеть, в нем женский род объединяется со средним, а мягкие основы всех типов практически не различают рода (в мягких типах М и $\mathrm{F} 2$ родовое различие отсутствует полностью). Но в реальном узусе и это стандартное распределение во многих случаях нарушается, демонстрируя взаимопроникновение «чужих» родовых окончаний во все типы: ср., например, такие «незаконные» формы генитива мн., как солдат, друзей, деревень, облаков, платьев, юношей, и т. п.). Фактически, в современном русском языке выбор из трех флексий генитива мн. числа является в большей степени лексико-фонологическим, чем грамматическим.

Похожая ситуация в номинативе мн.: стандартной является флексия $-a$ для типов $\mathrm{N}$ и $\mathrm{N} 2$ и флексия -y для всех остальных типов ${ }^{8}$. Однако, как известно, и это распределение часто нарушается: (ударная) флексия -á активно проникает в парадигмы существительных мужского рода (процесс появление форм типа дома́, города́ подробно изучен в исторической русистике; с другой стороны, имеется и непродуктивная модель типа стулья, с особой основой мн. числа). Верно и обратное: «чужая» флексия возможна и у существительных среднего рода (формы типа яблоки, плечи).

Таким образом, если в целом и можно согласиться с осторожным замечанием А. А. Зализняка (1967a/2002: 219), что из структуры именных парадигм «не следует, что различия морфологических родов во мн. числе в современном языке уже стерты», то вместе с тем нельзя и утверждать, что флексии мн. числа полностью детерминированы морфологическим родом. Самым нетривиальным описательным выводом из этого факта является то, что парадигма мн. числа оказывается в русском склонении элементом того же порядка, что «родовые» парадигмы ед. числа: если принять, что морфологический род во мн. числе не различается, то число и род становятся иерархическими единицами одного порядка в рамках набора парадигматических классов. Этот набор включает мужские, женские, средние и плюральные парадигмы, которые - опять же через призму табличной логики - могут быть представлены как смежные столбцы одной таблицы склонения. Несколько упрощая ситуацию, можно сказать, что в современном русском языке мн. число в структурном отношении стало подобно роду (или, если угодно, стало особым дополнительным родом).

8 Небольшое число существительных имеют особую флексию -е (иыгане, бояре). Проникновение вокалического элемента - $a$ - во все флексии множественного числа зашло в современном русском настолько далеко, что позволяет говорить о начавшемся процессе «декумуляции» плюральной падежной парадигмы с появлением элементов слабой агглютинации (см. подробнее Зализняк 1967b/2002; ср. также в более общем плане Igartua 2015, Плунгян \& Семёнова 2016, где понятие декумуляции обсуждается на более широком типологическом материале). 
Несмотря на кажущуюся парадоксальность этой формулировки, она никоим образом не является новой. Сходные идеи впервые, как представляется, были намечены в ранних работах Н. Н. Дурново начала 1920-х гг. об эволюции русского склонения и получили поддержку Н. С. Трубецкого. Примечательны несколько отрывков из опубликованных писем Трубецкого к Дурново (цит. по изд. Письма 2004); ср., в частности:

«Не кажется ли Вам, что в русском языке “множественное число” есть категория не числа, а рода? Мне кажется, что термин “множественное число" по крайней мере в русском языке совершенно неточен. Можно говорить лишь о “одушевленномножественном" и “неодушевленномножественном” родах, понимая эти термины так же условно, как и обозначения других родов: “ворота" принадлежит к неодушевленномножественному роду, но столь же мало связано с представлением о множественности, как “дверь”, принадлежащее к женскому роду, связано с представлением о женском поле. Наличие пар “стол : столы”, “дерево : деревья” и проч. есть частный случай, точно так же как наличие пар “немец : немка”, “дурак : дура” и проч. В общем же, в принципе “множественное число” в русском языке независимо от “единственного”».

(письмо Н. С. Трубецкого к Н. Н. Дурново от 24 февраля 1925)

«Мои мысли о “множественном роде” навеяны изучением восточнокавказских языков, где категория рода (в чеченском языке родов 6, в большинстве лезгинских - по 4) более семасиологична, чем в индоевропейских и где, между прочим, почти все “множественные числа" существительных принадлежат другому роду, чем соответственные "единственные числа". <..> Словом, в кавказских языках это явление обычное. Славянские же языки <...> проявляют тенденцию с одной стороны к “семантизации” родовых различий, с другой - к их подчеркиванию особыми формами склонения. В этом отношении они более всего приближаются к кавказскому типу, мне кажется, что в русском языке в этом направлении достигнут, если не максимум, то, во всяком случае, значительный успех».

(письмо Н. С. Трубецкого к Н. Н. Дурново от 8 марта 1925)

Наблюдения Трубецкого о структурном сходстве сингулярных родовых и плюральных парадигм представляются справедливыми, как и проницательное типологическое сравнение русского склонения с системами языков с именными классами (к нахско-дагестанским языкам можно было бы добавить и многочисленные примеры атлантических и вольта-конголезских языков Тропической Африки). В практике описания всех этих языков именной класс (понимаемый как уникальная согласовательная модель) обычно приписывается формам только одной числовой граммемы: у форм ед. и мн. числа разная согласовательная модель, а корреляции между сингулярными и плюральными классами обычно сложны и многообразны. Используя формулировку Трубецкого, во всех этих случаях «множественное число независимо от единственного» (по крайней мере в отношении выбора согласовательной модели). Проявления этой независимости в разных языках могут быть разными, но и в русском, и в многочисленных языках с именными классами это парадоксальным образом означает, что иерархически число подчинено роду — в отличие, например, от систем других сла- 
вянских или романских языков, где эти категории (более) равноправны и ни одна из них не доминирует над другой.

Как представляется, идеи Дурново и Трубецкого о возможной трактовке мн. числа как одной из граммем морфологического рода отчасти повлияли и на описание слов pluralia tantum у Зализняка (где лексемам типа сани приписывается особый согласовательный класс, называемый также «парным родом»). Здесь происходит такое же структурное отождествление числа и рода, точнее, переинтерпретация как родового изначально числового противопоставления. Подобное решение было бы в принципе невозможно, если бы в русском языке число и род сохранили иерархическое равноправие (и, например, слова pluralia tantum могли бы противопоставляться по роду, как это имеет место в других славянских языках). Единственный рудимент такого противопоставления можно было бы видеть в выборе разных алломорфов флексии номинатива и особенно генитива мн. (ср. ген. мн. каникул, чернил, брюк, но штанов, обоев, финансов), однако связывать этот выбор с родом, как мы видели, с трудом удается даже у стандартных существительных с полной числовой парадигмой - отсутствие такой мотивации у слов pluralia tantum (где этот выбор в современном языке явным образом лексический) является еще одним подтверждением иерархической доминации рода над числом9 ${ }^{9}$

Всё сказанное можно обобщить в виде следующей таблицы (табл. 1), где приводятся основные варианты флексий русских существительных (используется морфонологическая запись, позволяющая устранить тривиальные чередования). Грамматический синкретизм по возможности отражается объединением смежных клеток таблицы. Об обозначениях парадигматических классов (напомним, что как один из них рассматривается и мн. число) см. выше.

Таблица 1

Базовые падежные формы (с Асс)

\begin{tabular}{|c|c|c|c|c|c|c|}
\hline & $\mathrm{F}$ & $\mathrm{F} 2$ & $\mathrm{M} 2 / \mathrm{N} 2$ & M & $\mathrm{N}$ & PL \\
\hline NOM & $-a$ & \multicolumn{3}{|c|}{$-\varnothing$} & \multirow{2}{*}{$-O$} & $-y,-a,(-e)$ \\
\hline ACC & $-u$ & \multicolumn{2}{|c|}{$-\varnothing$} & DIF & & DIF \\
\hline GEN & \multicolumn{3}{|c|}{$-y$} & \multicolumn{2}{|c|}{$-a$} & $-\varnothing,-o v,-e j$ \\
\hline $\mathrm{PR}$ & \multirow{2}{*}{$-e$} & \multirow{2}{*}{\multicolumn{2}{|c|}{$-y$}} & \multicolumn{2}{|c|}{$-e$} & $-a x$ \\
\hline DAT & & & & \multicolumn{2}{|c|}{$-u$} & $-a m$ \\
\hline INS & $-o j[u]$ & $-j u$ & & $-o m$ & & -ami, (-mi) \\
\hline
\end{tabular}

9 А. А. Зализняк, тем не менее, не заходит так далеко в своем описании, чтобы считать плюральную парадигму манифестацией морфологического рода: поэтому и слова pluralia tantum в его концепции выражают лишь отдельную граммему синтаксического рода, а морфологический род им, во многом условно, приписывается в соответствии с представлениями о «стандартном» наборе флексий Nom и Gen (так, например, слова сани и сени получают в Грамматическом словаре помету мужского морфологического рода, каникуль и брюки - женского морфологического рода). 
Примеры класса F: стена, ступня, коза, юноша

Примеры класса F2: кровь, мышь, лошадь, пять

Примеры класса N2: знамя (класс M2: путь)

Примеры класса М: бык, меч, дом

Примеры класса N: озеро, яблоко, поле, чудовище

\section{4. Место форм партитива и аднумератива в парадигме}

Помимо базовых падежей, определенный интерес с точки зрения «встраивания» в таблицу склонения представляют также слабо дифференцированные, но парадигматически существенные падежи. Напомним, что таких падежей три; место Асс уже было определено в Таблице 1 среди базовых падежей, тогда как проблема Part и Adn актуальна лишь для существительных мужского морфологического рода стандартного типа склонения (во всех остальных типах специализированных показателей у этих падежей нет, и они совпадают с Gen). Таким образом, эти два падежа целесообразно отразить в особой таблице, представляющей собой локальное расширение базовой таблицы для типа М.

На первый взгляд эта задача кажется тривиальной: в базовую падежную таблицу нужно просто добавить две лишние строки. Однако такой наиболее традиционный - вариант описания оказывается не единственно возможным (и, в силу ряда факторов, даже не самым предпочтительным). Дело в том, что основная проблема, которая возникает в связи с формами Part и Adn, состоит в том, граммемами какой категории их целесообразнее всего считать. Выбор здесь, собственно, возможен из двух трактовок: более формальная трактовка исходит из того, что это дополнительные падежные граммемы (как это обычно молчаливо принимается в существующих описаниях), но учет семантической специфики этих показателей заставляет рассмотреть их непадежную трактовку в качестве пусть и спорной, но интересной альтернативы. В последнем случае следует исходить из того, что основные значения Part и Adn - количественные: они выражают значения из семантической зоны квантификации (неопределенного количества вещества, небольшого количества дискретных объектов и т. п.). Тот факт, что партитивность и счетность - фактически количественные, а не падежные значения (поскольку, в отличие от падежных, они никак не связаны с выражением семантических и/или синтаксических ролей аргументов предиката), вообще говоря, хорошо известен. В тех языках, где партитив надежным образом встраивается в падежную систему, он, как правило, выражает (пусть в ограниченном объеме) и собственно падежные функции. Однако в русском языке положение иное: функции Part и Adn ограничены количественной сферой. Это отмечается уже у А. А. Зализняка: «<..> различие между предметом вообще и некоторой его частью в принципе сходно с различием чисел и потому могло бы трактоваться аналогично числу» (Зализняк 1967a/2002: 46; ср. также Мельчук 1985); однако Зализняк (возможно, 
справедливо) не делает радикальных дескриптивных выводов из этого фак$\mathrm{Ta}^{10}$. Между тем, такой вариант описания, при котором граммемы Part и Adn образуют общую категорию с ед. и мн. числом, может быть рассмотрен в некотором отношении он лучше отражает не только семантическую, но и синтаксическую специфику употребления Part и Adn. Однако здесь необходимо учитывать несколько важных обстоятельств.

Прежде всего, выражение Part и Adn возможно только в «главных» синтаксических падежах, т. е. оно семантически релевантно для Nom, Acc и Gen, а в других падежах не выражается ${ }^{11}$ (в партитивных контекстах, если о них вообще можно говорить применительно к косвенным падежам, используется форма ед. числа соответствующего падежа, а в счетных контекстах - форма мн. числа соответствующего падежа).

При этом морфологической особенностью Adn является то, что в тех немногих существительных типа М, где у него имеется специализированный показатель, он присутствует только в формах Nom (и Aсc, если он совпадает с Nom), а в остальных падежах совпадает с показателями мн. числа для этих падежей. Cp. прошли/провёл два часа́ vs. прошли/ провёл эти часы (здесь в контексте Nom и Асс различается аднумеративная и плюральная формы), но $\kappa$ двум/к этим часам (здесь в контексте косвенного падежа аднумеративная и плюральная формы не различаются).

Несколько иначе ведет себя Part: он имеет специализированный показатель во всех трех главных падежах, но само падежное противопоставление при этом нейтрализуется, т. е. этот специализированный показатель y Part во всех трех падежах одинаков. Ср. партитивные употребления лексемы сахар в контексте Nom, Acc и Gen: сахару там былл!.. (Nom), добавь еще сахару (Acc), кусочек сахару (Gen). Грамматический анализ этих примеров может показать спорным, но следует напомнить, что мы анализируем партитив как чисто количественную граммему, следовательно, вопрос о приписывании падежа зависит от синтаксической функции имени - а она в приведенных примерах разная (соответственно, субъектная, объектная и атрибутивная). Тем самым, и падежи словоформе сахару в этих контекстах следует приписывать разные, хотя формальное различие в выражении падежных функций отсутствует, так как блокируется партитивом (более подробное обсуждение этих проблем в контексте современных синтакси-

10 Как представляется, наиболее существенным препятствием для непадежной трактовки Part и Adn является не столько даже их слабая морфологическая дифференцированность (и лексическая ограниченность), сколько необязательность их употребления: так, практически во всех контекстах Part может быть заменен на Gen. Постулировать же «расщепление» показателя Gen на две граммемы - падежную и непадежную - является, по-видимому, слишком громоздким и антиинтуитивным решением (что, впрочем, не отменяет того факта, что среди употреблений русского Gen значительное место занимают такие, которые не выражают ролевых отношений).

$11 \mathrm{C}$ типологической точки зрения случаи нейтрализации количественных противопоставлений в части падежей вполне обычны, и в этом смысле количественная трактовка Part и Adn не противоречит известным фактам. 
ческих теорий см., например, в Madariaga \& Igartua 2017 и Igartua \& Madariaga 2018; с типологической точки зрения это явление в русском падежном морфосинтаксисе ближе всего соответствует так называемым «generalized partitives», которые блокируют выражение главных синтаксических ролей: cp. Seržant 2021: 890-892).

С учетом сказанного, возможный вариант расширенной падежной таблицы для лексем класса М мог бы выглядеть так, как это показано в Таблице 2.

Таблица 2

Расширенная таблица для существительных типа М

\begin{tabular}{c|c|c|c|c}
\hline & SG & PART & PL & ADN \\
\hline NOM & $-\varnothing$ & \multirow{3}{*}{$-u$} & $-y,-a ́$ & $-a,(-a ́)$ \\
\cline { 1 - 1 } ACC & DIF & \multicolumn{2}{|c}{ DIF } \\
\cline { 1 - 1 } GEN & $-a$ & & \multicolumn{2}{|c|}{$-o v /-e j$} \\
\hline
\end{tabular}

Конечно, эта таблица выглядит во многом необычно - но заметим, что она может существенно упростить синтаксическое описание русских количественных конструкций. В частности, предложенная в ней трактовка позволяет во всех случаях считать имя синтаксической вершиной нумеративной конструкции - и говорить, например, об именительном (а не родительном) падеже аднумеративного подлежащего в конструкциях типа стоят два до́ма - аналогично именительному падежу плюрального подлежащего в конструкциях типа стоят эти дома́. Аналогичные решения для партитивных именных групп обсуждались выше; типологическим закономерностям, выявленным у партитивных граммем в языках мира, они не противоречат.

Таким образом, как мы попытались показать, техническая на первый взгляд задача составления «оптимальной» таблицы склонения открывает ряд нетривиальных закономерностей в устройстве русского именного словоизменения и позволяет с неожиданной стороны взглянуть на типологические особенности русского языка.

\section{ЛИТЕРАТУРА}

Аркадьев П. М. «Типология и диахрония: наблюдения над падежным синкретизмом в славянских языках». В. Н. Топоров (ред.). Язык. Личность. Текст. Сборник статей к 70летию Т. М. Николаевой. Москва: Языки славянских культур, 2005: 210-223.

Даниэль М. А. «“Новый” русский вокатив: история формы усеченного обращения сквозь призму корпуса письменных текстов». К. Л. Киселёва и др. (ред.). Корпусные исследования по русской грамматике. Москва: Пробел, 2009: 224-244.

Зализняк А. А. «Русское именное словоизменение». А. А. Зализняк. Русское именное словоизменение (с приложением избранных работ по современному русскому языку и общему языкознанию), Москва: Языки русской культуры, 1967a/2002: 1-370.

Зализняк А. А. «О показателях множественного числа в русском склонении». А. А. Зализняк. Русское именное словоизменение (с приложением избранных работ по совре- 
менному русскому языку и общему языкознанию). Москва: Языки русской культуры, 1967b/2002: 545-549.

Зализняк А. А. «О понимании термина «падеж» в лингвистических описаниях». А. А. Зализняк. Русское именное словоизменение (с приложением избранных работ по современному русскому языку и общему языкознанию). Москва: Языки русской культуры, 1973/2002: 613-647.

Крылов С. А. «"Русское именное словоизменение” А. А. Зализняка 30 лет спустя: опыт ретроспективной рецензии с позиций нео-структуралистской морфологии». А. А. Зализняк. Русское именное словоизменение (с приложением избранных работ по современному русскому языку и общему языкознанию). Москва: Языки русской культуры, 2002: 699-748.

Малышева А. В. \& Ронько Р. В. «Русский объектный генитив при отрицании по данным диалектных корпусов и устного корпуса НКРЯ». Вопросы языкознания 4 (2020): 25-54.

Мельчук И. А. Поверхностный синтаксис русских числовых выражений. Wien: Wiener Slawistischer Almanach, 1985.

Плунгян В. А. \& Семёнова Кс. П. «К типологии древнеармянской именной парадигматики: Instr.Pl.». Вопросы языкознания 5 (2016): 103-118.

Письма и заметки Н. С. Трубеикого. Подготовка к изд. Р. Якобсона при участии Х. Барана, О. Ронена, М. Тейлор. Москва: Языки славянских культур, 2004.

Andersen Henning. "The new Russian vocative: Synchrony, diachrony, typology”. Scando-Slavica 58/1 (2012): 122-167.

Arkadiev Peter M. "Syncretisms and neutralizations involving morphological case: Challenges for markedness theory". Alexander Arkhipov \& Patience Epps (eds.), New Challenges in Typology: Transcending the Borders and Refining the Distinctions. Berlin: Mouton de Gruyter, 2009: 105-126.

Auwera Johan van der. "Semantic maps, for synchronic and diachronic typology". Anna Giacalone Ramat, Caterina Mauri \& Piera Molinelli (eds.), Synchrony and Diachrony: A dynamic interface. Amsterdam: John Benjamins, 2013: 153-176.

Baerman Matthew, Dunstan Brown \& Greville G. Corbett. The Syntax-Morphology Interface: A Study of Syncretism. Cambridge: Cambridge University Press, 2005.

Blevins James P. Word and paradigm morphology. Oxford: Oxford University Press, 2016.

Caha Pavel. "Classical Armenian declension". Nordlyd 36/1 (2009): 77-112.

Chvany Catherine V. "Hierarchies in the Russian case system: For N-A-G-L-D-I, against N-GD-A-I-L”. Olga T. Yokoyama \& Emily Klenin (eds.). Selected Essays of Catherine V. Chvany, Columbus (OH): Slavica, 1982/1996: 175-187.

Daniel Michael. "The second genitive in Russian". Silvia Luraghi \& Tuomas Huumo (eds.), Partitive Cases and Related Categories, Berlin: De Gruyter Mouton, 2014: 347-378.

Georgakopoulos Thanasis \& Stéphane Polis. "The semantic map model: State of the art and future avenues for linguistic research". Language and Linguistics Compass 12/2 (2018).

Harley Heidi \& Elizabeth Ritter. "Person and Number in Pronouns: A Feature-Geometric Analysis". Language 78/3 (2002): 482-526.

Haspelmath Martin. 2003. "The geometry of grammatical meaning: Semantic maps and crosslinguistic comparison". Michael Tomasello (ed.). The new psychology of language. Vol. II. Mahwah, NJ: Lawrence Erlbaum, 2003: 211-242.

Igartua Iván. "From cumulative to separative exponence in inflection: Reversing the morphological cycle”. Language 91 (2015): 676-722.

Igartua Iván \& Nerea Madariaga. "The interplay of semantic and formal factors in Russian morphosyntax: animate paucal constructions in direct object function". Russian Linguistics 42/1 (2018): 27-55.

Janda Laura A. "Name-calling: The Russian 'new Vocative' and its status". Lars Heltoft, Iván Igartua, Brian D. Joseph, Kirsten Jeppesen Kragh \& Lene Schøsler (eds.). Perspectives on Language Structure and Language Change: Studies in honor of Henning Andersen. Amsterdam: John Benjamins. 2019: 381-394.

Koptjevskaja-Tamm Maria \& Wälchli Bernhard. 2001. "The Circum-Baltic languages: An arealtypological approach". Östen Dahl \& Maria Koptjevskaja-Tamm (eds.). Circum-Baltic Languages: Volume 2: Grammar and Typology. Amsterdam: John Benjamins, 2001: 615-750.. 
Madariaga Nerea \& Igartua Iván. "Idiosyncratic (Dis)agreement Patterns: The Structure and Diachrony of Russian Paucal Subjects". Scando-Slavica 63/2 (2017): 99-132.

McCreight Katherine \& Chvany Catherine V. 1991. "Geometric representation of paradigms in a modular theory of grammar". Frans Plank (ed.). Paradigms: The Economy of Inflection. Berlin: Mouton de Gruyter, 1991: 91-112.

Nesset Tore. "The Assignment of Gender and Declension to Russian Nouns in Soft Consonants: Predictability and Rule Interaction". Journal of Slavic Linguistics 11/2 (2003): 287-322.

Plank Frans. 1991. "Rasmus Rask's dilemma". Frans Plank (ed.). Paradigms: The Economy of Inflection. Berlin: Mouton de Gruyter, 1991: 161-196.

Seržant Ilja A. 2021. "Typology of partitives". Linguistics 59/4 (2021): 881-947.

\section{REFERENCES}

Andersen Henning. "The new Russian vocative: Synchrony, diachrony, typology". Scando-Slavica 58/1 (2012): 122-167.

Arkadiev Peter M. "Syncretisms and neutralizations involving morphological case: Challenges for markedness theory". Alexander Arkhipov \& Epps Patience (eds.), New Challenges in Typology: Transcending the Borders and Refining the Distinctions. Berlin: Mouton de Gruyter, 2009: 105-126.

Arkad'ev P. M. «Tipologiya i diahroniya: nablyudeniya nad padezhnym sinkretizmom v slavyanskih yazykah». V. N. Toporov (red.). Yazyk. Lichnost’. Tekst: sb. st. k 70-letiyu T. M. Nikolaevoj. Moskva: Yazyki slavyanskih kul'tur, 2005: 210-223.

Auwera Johan van der. "Semantic maps, for synchronic and diachronic typology". Anna Giacalone Ramat, Caterina Mauri \& Piera Molinelli (eds.), Synchrony and Diachrony: A dynamic interface. Amsterdam: John Benjamins, 2013: 153-176.

Baerman Matthew, Dunstan Brown \& Corbett Greville G. The Syntax-Morphology Interface: A Study of Syncretism. Cambridge: Cambridge University Press, 2005.

Blevins James P. Word and paradigm morphology. Oxford: Oxford University Press, 2016.

Caha Pavel. "Classical Armenian declension". Nordlyd 36/1 (2009): 77-112.

Chvany Catherine V. "Hierarchies in the Russian case system: For N-A-G-L-D-I, against N-GD-A-I-L”. Olga T. Yokoyama \& Emily Klenin (eds.). Selected Essays of Catherine V. Chvany, Columbus (OH): Slavica, 1982/1996: 175-187.

Daniel' M. A. «"Novyj” russkij vokativ: istoriya formy usechennogo obrashcheniya skvoz' prizmu korpusa pis'mennyh tekstov». K. L. Kiselyova et al. (red.). Korpusnye issledovaniya po russkoj grammatike. Moskva: Probel, 2009: 224-244.

Daniel Michael. "The second genitive in Russian". Silvia Luraghi \& Tuomas Huumo (eds.), Partitive Cases and Related Categories, Berlin: De Gruyter Mouton, 2014: 347-378.

Georgakopoulos Thanasis \& Stéphane Polis. 2018. "The semantic map model: State of the art and future avenues for linguistic research". Language and Linguistics Compass 12/2 (2018).

Harley Heidi \& Elizabeth Ritter. "Person and Number in Pronouns: A Feature-Geometric Analysis". Language 78/3 (2002): 482-526.

Haspelmath Martin. 2003. "The geometry of grammatical meaning: Semantic maps and crosslinguistic comparison". Michael Tomasello (ed.). The new psychology of language. Vol. II. Mahwah, NJ: Lawrence Erlbaum, 2003: 211-242.

Igartua Iván. "From cumulative to separative exponence in inflection: Reversing the morphological cycle". Language 91 (2015): 676-722.

Igartua Iván \& Nerea Madariaga. "The interplay of semantic and formal factors in Russian morphosyntax: animate paucal constructions in direct object function". Russian Linguistics 42/1 (2018): 27-55.

Janda Laura A. "Name-calling: The Russian 'new Vocative' and its status”. Lars Heltoft, Iván Igartua, Brian D. Joseph, Kirsten Jeppesen Kragh \& Lene Schøsler (eds.). Perspectives on Language Structure and Language Change: Studies in honor of Henning Andersen. Amsterdam: John Benjamins. 2019: 381-394.

Koptjevskaja-Tamm Maria \& Bernhard Wälchli. 2001. "The Circum-Baltic languages: An arealtypological approach”. Östen Dahl \& Maria Koptjevskaja-Tamm (eds.). Circum-Baltic Languages: Volume 2: Grammar and Typology. Amsterdam: John Benjamins, 2001: 615-750. 
Krylov S. A. «"Russkoe imennoe slovoizmenenie” A. A. Zaliznyaka 30 let spustya: opyt retrospektivnoj recenzii s pozicij neo-strukturalistskoj morfologii». A. A. Zaliznyak. Russkoe imennoe slovoizmenenie (s prilozheniem izbrannyh rabot po sovremennomu russkomu yazyku i obshchemu yazykoznaniyu). Moskva: Yazyki russkoj kul'tury, 2002: 699-748.

Madariaga Nerea \& Iván Igartua. "Idiosyncratic (Dis)agreement Patterns: The Structure and Diachrony of Russian Paucal Subjects". Scando-Slavica 63/2 (2017): 99-132.

Malysheva A. V. \& R. V. Ron'ko. «Russkij ob”ektnyj genitiv pri otricanii po dannym dialektnyh korpusov i ustnogo korpusa NKRYA». Voprosy yazykoznaniya 4 (2020): 25-54.

McCreight Katherine \& Catherine V. Chvany. 1991. "Geometric representation of paradigms in a modular theory of grammar". Frans Plank (ed.). Paradigms: The Economy of Inflection. Berlin: Mouton de Gruyter, 1991: 91-112.

Mel'chuk I. A. Poverhnostnyj sintaksis russkih chislovyh vyrazhenij. Wien: Wiener Slawistischer Almanach, 1985.

Nesset Tore. "The Assignment of Gender and Declension to Russian Nouns in Soft Consonants: Predictability and Rule Interaction". Journal of Slavic Linguistics 11/2 (2003): 287-322.

Pis'ma i zametki N. S. Trubeckogo. Podgotovka k izd. R. Yakobsona pri uchastii H. Barana, O. Ronena, M. Tejlor. Moskva: Yazyki slavyanskih kul'tur, 2004.

Plank Frans. 1991. "Rasmus Rask's dilemma". Frans Plank (ed.). Paradigms: The Economy of Inflection. Berlin: Mouton de Gruyter, 1991: 161-196.

Plungyan V. A. \& Ks. P. Semyonova. «K tipologii drevnearmyanskoj imennoj paradigmatiki: Instr.Pl.». Voprosy yazykoznaniya 5 (2016): 103-118.

Seržant Ilja A. 2021. "Typology of partitives". Linguistics 59/4 (2021): 881-947.

Zaliznyak A. A. «Russkoe imennoe slovoizmenenie». A. A. Zaliznyak. Russkoe imennoe slovoizmenenie (s prilozheniem izbrannyh rabot po sovremennomu russkomu yazyku i obshchemu yazykoznaniyu). Moskva: YAzyki russkoj kul'tury, 1967a/2002: 1-370.

Zaliznyak A. A. «O pokazatelyah mnozhestvennogo chisla v russkom sklonenii». A. A. Zaliznyak. Russkoe imennoe slovoizmenenie (s prilozheniem izbranny rabot po sovremennomu russkomu yazyku i obshchemu yazykoznaniyu). Moskva: Yazyki russkoj kul'tury, 1967b/2002: 545-549.

Zaliznyak A. A. «O ponimanii termina "padezh" v lingvisticheskih opisaniyah». A. A. Zaliznyak. Russkoe imennoe slovoizmenenie (s prilozheniem izbranny rabot po sovremennomu russkomu yazyku i obshchemu yazykoznaniyu). Moskva: Yazyki russkoj kul'tury, 1973/2002: 613-647.

\section{Владимир Плунгјан}

\section{ГЕОМЕТРИЈА ПРОМЕНЕ РЕЧИ У РУСКОМ ЈЕЗИКУ: О ТРАДИЦИОНАЛНИМ И НЕТРАДИЦИОНАЛНИМ ТАБЛИЦАМА ИМЕНИЧКЕ ПРОМЕНЕ}

Резиме

У раду се разматра низ теоријских проблема промене речи у руском језику са становишта техничког (на први поглед) задатка формирања оптималне таблице промена именица у руском језику. Те потешкоће се могу поделити у три групе. Прву групу чини хијерархија падешких грамема и повезани с њом редослед падежа у парадигми. Другу групу чини скуп врста̄ промена̄ (типови промена речи који настају услед аломорфних варијација показатеља који одражавају једнак скуп грамема), као и представљање тих аломорфних варијација у парадигмама промена речи. Најзад, у трећу групу спадају потешкоће при одређивању места форми партитива („другог генитива”) и аднумератива („бројне форме”) у систему промене именица у руском језику. Та потешкоћа је у русистици разматрана кудикамо мање, али она је тесно повезана са потешкоћама из двеју претходних група.

Кључне речи: руски језик, морфологија, промена именица, падеж, број, род, геометријски модели, таблице. 